\title{
Pengaruh Gaya Kepemimpinan terhadap Motivasi Kerja Karyawan Departemen Housekeeping di Hotel A Ubud
}

\author{
Ni Putu Diah Sri Maharani'1 , I Gusti Ayu Putu Wita Indrayani2*, Desak Made Santi Diwyarthi ${ }^{3}$
}

\author{
1,3Program Studi Administrasi Perhotelan, Politeknik Pariwisata Bali \\ 2Program Studi Manajemen Divisi Kamar, Politeknik Pariwisata Bali
}

Jl. Dharmawangsa Kampial, Nusa Dua Bali
1diah.maharani17@gmail.com, 22wita.indrayani@ppb.ac.id, ${ }^{3}$ santidiwyarthi@yahoo.com *Corresponding author

\author{
\begin{tabular}{l|l|l} 
Received: Mei, 2021 & Accepted: Mei, 2021 & Published: June, 2021
\end{tabular}
}

\begin{abstract}
The competition in this industry has become extremely tight as the number of star and nonstar hotels in Bali increased in 2019, reaching 4,323 hotels. The goal of this study was to examine the impact of the leadership style on the work motivation of employees in the Hotel A Ubud's Housekeeping Department. The participants in this study were all employees of the Hotel A Ubud's Housekeeping Department. In this study, a saturated sample or census technique was used for sampling. In this study, simple regression analysis was used for data analysis. The analysis results show that leadership style has a positive and significant effect on employee work motivation. As a result, the better the application of a leadership style in a company, the higher the work motivation. The findings of this study have implications for the development of hotel policies aimed at increasing employee work motivation by paying attention to the leader's style and character while leading his subordinates. However, it is expected that future research will examine the effect of these two variables on a broader scope using a longitudinal approach, so that the research results can be generalized.
\end{abstract}

Keywords: leadership style, work motivation, housekeeping

\begin{abstract}
Abstrak
Meningkatnya jumlah hotel bintang dan non bintang di Bali pada tahun 2019 yang mencapai 4.323 hotel, membuat persaingan dalam industri ini menjadi demikian ketat.. Tujuan penelitian ini adalah untuk menganalisis pengaruh gaya kepemimpinan terhadap motivasi kerja karyawan Departemen Housekeeping di Hotel A Ubud. Populasi dalam penelitian ini adalah seluruh karyawan Departemen Houesekeeping di Hotel A Ubud. Pengambilan sampel dalam penelitian ini menggunakan teknik sampel jenuh atau sensus. Teknik analisis data dalam penelitian ini menggunakan analisis regresi sederhana. Hasil analisis menunjukkan bahwa gaya kepemimpinan berpengaruh positif dan signifikan terhadap motivasi kerja. Hasil ini berarti bahwa semakin baik penerapan gaya kepemimpinan pada sebuah perusahaan, maka dapat membentuk motivasi kerja yang semakin tinggi. Hasil penelitian ini berimplikasi pada formulasi kebijakan hotel dalam meningkatkan motivasi kerja karyawan dengan memperhatikan gaya serta karakter pemimpin dalam memimpin bawahannya. Namun demikan, untuk pengembangan
\end{abstract}


Pengaruh Gaya Kepemimpinan terhadap Motivasi Kerja Karyawan Departemen Housekeeping di Hotel A Ubud

Maharani, Indrayani, Diwyarthi

penelitian selanjutnya, diharapkan dapat meneliti pengaruh dua variabel ini dalam ruang lingkup yang lebih luas dengan pendekatan longitudinal, sehingga hasil penelitian dapat digeneralisasi.

Kata kunci: gaya kepemimpinan, motivasi kerja, housekeeping

\section{PENDAHULUAN}

Pariwisata Bali adalah salah satu destinasi yang terkenal baik di Indonesia maupun mancanegara. Data dari Badan Pusat Statistik tahun 2009 menunjukkan jumlah kunjungan wisatawan mancanegara ke Bali selama 7 tahun terakhir yakni dari tahun 2013 hingga 2019 terus mengalami peningkatan, dengan tingkat pertumbuhan yang tidak tetap antara 6-23\%. Meningkatnya jumlah wisatawan ke Bali tersebut menyebabkan industri wisata seperti hotel dan restoran di Bali juga mengalami peningkatan. Hotel A Ubud merupakan salah satu hotel di Ubud yang turut merasakan ketatnya persaingan industri hotel di Bali. Berbagai cara harus dilakukan oleh Hotel A Ubud untuk terus dapat diterima oleh pasar dan bersaing dengan kompetitornya, mulai dari penetapan harga kamar, fasilitas dan benefit yang ditawarkan serta kualitas pelayanan yang diberikan.

Karyawan memiliki peranan penting sebagai asset hotel yang sangat berharga untuk bisa mencapai tujuan yang telah ditetapkan tersebut. Persaingan industri perhotelan semakin ketat, sehingga hotel harus mampu memberdayakan karyawannya secara positif agar dapat menunjukan kinerja yang maksimal sehingga mampu menciptakan keunggulan daya saing dengan para kompetitornya. Salah satu kunci keunggulan kompetitif potensial ini adalah karyawan yang memiliki motivasi kerja yang tinggi (Simamora, 2014). Sebaliknya, karyawan dengan motivasi kerja yang rendah akan berimplikasi negatif pada kinerja hotel secara keseluruhan karena karyawan tidak akan mengeluarkan usaha yang maksimal dalam melaksanakan pekerjaan. Fenomena motivasi kerja ini yang diamati peneliti pada Hotel A Ubud, khususnya Departemen Housekeeping.

Banyak hal yang dapat diperhatikan untuk melihat indikasi motivasi kerja karyawan. Salah satunya adalah kedisplinan kehadiran. Motivasi kerja karyawan erat kaitannya dengan tingkat absensi karyawan, yakni apabila karyawan memiliki motivasi kerja yang tinggi tentu akan rajin dalam bekerja, sedangkan karyawan yang memiliki motivasi kerja rendah cenderung akan sering absen dalam bekerja (Supriadi, 2017:60). Permasalahan motivasi kerja karyawan yang terjadi pada Hotel A Ubud dapat dilihat dari gejala disiplin kerja seperti beberapa pegawai sering bolos atau tidak masuk kantor ketika atasannya sedang tidak berada di kantor karena ada perjalanan dinas keluar daerah. Tingkat absensi pegawai Hotel A Ubud, khususnya Departemen Housekeeping, dari Januari sampai Desember 2019 mengalami fluktuasi setiap bulannya.

Absensi yang menjadi permasalahan bagi Hotel A Ubud adalah pegawai yang tidak bekerja tanpa ada keterangan, serta ijin kerja yang sudah melebihi batas cuti yang ditentukan. Data absensi tersebut di luar dari Day off (DO) atau Day off Payment (DP) yang merupakan hak karyawan. Berdasarkan wawancara dengan HR Manager Hotel A Ubud, rata-rata tingkat absensi pegawai setiap bulan adalah 3,13 persen yang tergolong tinggi. Hal ini dikuatkan oleh Flippo (2001:281) yang menyatakan bahwa tingkat absensi nol sampai dengan dua persen dinyatakan baik, tiga hingga sepuluh persen dinyatakan tinggi, dan lebih dari sepuluh persen dinyatakan tidak wajar. Semakin tinggi tingkat absensi akan berimplikasi terhadap rendahnya kinerja karyawan (Safitri, 2018). Tingkat absensi karyawan departemen housekeeping Hotel A Ubud Tahun 2019 menunjukkan rata-rata absensi di atas tiga persen sehingga mengindikasikan tingkat absensi dinyatakan tinggi. Apabila tingkat kehadiran karyawannya kurang dari standar hari kerja yang ditetapkan maka karyawan tersebut tidak akan mampu memberikan kontribusi yang optimal terhadap organisasi. 
Pengaruh Gaya Kepemimpinan terhadap Motivasi Kerja Karyawan Departemen Housekeeping di Hotel A Ubud Maharani, Indrayani, Diwyarthi

Selain tingkat absensi yang cenderung tinggi, Hotel A Ubud juga baru saja mengalami pergantian pimpinan / manajer baru pada Departemen Housekeeping. Berdasarkan hasil wawancara dengan salah satu karyawan Housekeeping, gaya kepemimpinan manajer baru ini merupakan salah satu kontributor menurunnya motivasi kerja karyawan, seperti misalnya ketidaktegasan dalam membuat keputusan, kurangnya pengawasan setelah pendelegasian tugas, serta kurangnya hubungan interpersonal antara pemimpin dan bawahan. Padahal dalam upaya untuk dapat unggul dari pesaing, peran seorang pemimpin sangat krusial. Seorang pemimpin atau kepala suatu bagian organisasi akan diakui sebagai seorang pemimpin jika dia dapat mengarahkan bawahannya kearah pencapaian tujuan organisasi (Chaerunnisa, 2016). Lebih lanjut dikemukakan bahwa kualitas hubungan antara pemimpin dengan bawahannya sangat penting dalam berbagai hal untuk memastikan kualitas performa dalam pekerjaannya.

Gaya kepemimpinan serta karakter pemimpin yang berbeda akan memberi dampak yang berbeda pula dalam suatu organisasi (Yukl, 2015; Rasheed et al., 2020). Seorang pemimpin harus mampu memberikan motivasi kepada bawahan agar dapat bekerja dengan baik dan efektif (Woszczyna, 2015). Gaya kepemimpinan yang efektif sangat dipengaruhi oleh kepribadian pemimpin (Al-Sada et al., 2017). Setiap pemimpin perlu memiliki aspek-aspek kepribadian yang dapat menunjang usahanya dalam mewujudkan hubungan manusia yang efektif dengan anggota organisasinya (Indrayani, 2018). Gaya kepemimpinan (leadership) adalah proses mempengaruhi atau memberi contoh kepada pengikut-pengikutnya (Wowor et al., 2019: 109). Peran utama pemimpin adalah mempengaruhi orang lain untuk mencapai tujuan yang telah ditetapkan (Surbakti, 2016), sehingga pemimpin Hotel A Ubud memegang peranan penting dan esensial dalam kemajuan perusahaan.

Seorang pemimpin harus mampu memberikan motivasi kepada bawahan agar dapat bekerja dengan baik dan efektif. Hubungan antara gaya kepemimpinan dengan motivasi kerja ini sudah dipaparkan oleh berbagai jurnal penelitian terdahulu, seperti penelitian yang dilakukan oleh Wibowo dan Prasetyo (2015), Afrizal (2016), Surbakti (2016), Supriadi dan Riswana (2017), Farfalonni dan Prasetio (2017), Kiswanto dan Sutarso (2018) yang menemukan hasil bahwa gaya kepemimpinan berpengaruh positif dan signifikan terhadap motivasi kerja pegawai, yang berarti semakin baik penerapan gaya kepemimpinan pada sebuah perusahaan, maka dapat membentuk motivasi kerja yang semakin tinggi. Hal ini dikarenakan pemimpin merupakan seorang role model bagi bawahannya yang mampu merefleksikan visi, misi, dan tujuan organisasi dalam bentuk konkret, sehingga karyawan akan termotivasi baik secara intrinsik maupun ekstrinsik untuk melakukan yang terbaik bagi organisasinya sesuai dengan arahan pemimpinnya.

Paparan yang telah diuraikan sebelumnya menunjukkan bahwa permasalahan yang terjadi terkait gaya kepemimpinan dan motivasi kerja karyawan perlu dikaji secara empiris untuk memastikan apakah gaya kepemimpinan memang mempengaruhi motivasi kerja karyawan Housekeeping di Hotel A Ubud. Penelitian ini difokuskan pada Departemen Housekeeping di Hotel A Ubud, karena Departemen Housekeeping merupakan departemen dengan karyawan terbanyak yang menangani produk utama hotel. Selain itu, adanya pergantian pemimpin yang baru-baru ini terjadi merupakan salah satu aspek yang perlu dilihat lebih detail pengaruhnya terhadap motivasi kerja karaywan. Maka dari itu, dirasa penting untuk melihat korelasi antara dua variabel ini, gaya kepemimpinan dan motivasi kerja, sehingga dapat memberikan gambaran lebih jelas mengenai apa yang sesungguhnya terjadi dan langkah yang dapat dilakukan oleh hotel A untuk perbaikan pelayanan ke depannya. 
Pengaruh Gaya Kepemimpinan terhadap Motivasi Kerja Karyawan Departemen Housekeeping di Hotel A Ubud Maharani, Indrayani, Diwyarthi

\section{METODE PENELITIAN}

\subsection{Populasi, Sample dan Pengumpulan Data}

Objek penelitian ini adalah gaya kepemimpinan dan motivasi kerja karyawan Departemen Housekeeping di Hotel A Ubud. Lokasi penelitian ini adalah pada Hotel A Ubud yang beralamat di Desa, Melinggih Kelod, Payangan, Gianyar, Bali. Jenis data yang digunakan dalam penelitian ini terbagi menjadi dua jenis, yaitu data kualitatif yang meliputi sejarah singkat dan gambaran umum organisasi Hotel A Ubud dan data kuantitatif terkait jumlah kunjungan wisatawan, data terkait absensi karyawan Hotel A Ubud, dan hasil kuesioner. Sumber data dalam penelitian ini terdiri dari sumber primer meliputi observasi, kuesioner, dan wawancara dengan pihak Hotel A Ubud, serta sumber sekunder yang meliputi studi dokumentasi dari Badan Pusat Statistik (BPS), buku, laporan, jurnal serta data absensi pegawai yang diperoleh dari HRD Hotel A Ubud. Kuisioner gaya kepemimpinan dibangun berdasarkan lima indikator perilaku pemimpin, yang terdiri dari perilaku instruktif, perilaku konsultatif, perilaku partisipatif, perilaku delegatif, dan perilaku suportif (Thoha (2014). Sedangkan, motivasi kerja dapat diukur berdasarkan tiga indikator, antara lain arahan perilaku, tingkat usaha, dan tingkat kegigihan (Kartika dan Kaihatu, 2010).

Populasi dalam penelitian ini adalah seluruh karyawan Departemen Houesekeeping di Hotel A Ubud. Pengambilan sampel dalam penelitian ini menggunakan teknik sampel jenuh atau sensus, dimana seluruh populasi penelitian akan dipilih menjadi responden penelitian (Sugiyono, 2016: 116). Teknik ini dipilih karena jumlah dari populasi tergolong kecil, sehingga seluruh populasi digunakan sebagai sampel dalam penelitian ini. Jumlah karyawan Departemen Housekeeping pada Hotel A Ubud adalah sebanyak 42 orang, sehingga jumlah responden penelitian yang digunakan dalam penelitian ini adalah sebanyak 42 orang.

Pengumpulan data dalam penelitian ini menggunakan metode kuisioner dan metode wawancara. Kuesioner yang digunakan dalam penelitian ini disebarkan secara online dengan menggunakan google form. Pengukuran data kuesioner dalam penelitian ini menggunakan skala likert 5 poin. Metode wawancara dilakukan dengan cara tanya jawab langsung dengan Manajer HRD dan karyawan Departemen Housekeeping Hotel A Ubud mengenai masalah yang akan diteliti. Pertanyaan yang akan diajukan seperti permasalahan mengenai gaya kepemimpinan dan motivasi kerja pegawai Hotel A Ubud.

\subsection{Definisi Operasional Variabel}

Gaya kepemimpinan adalah pola perilaku yang ditunjukkan oleh pemimpin dalam mempengaruhi orang lain. Indikator gaya kepemimpinan dalam penelitian ini mengacu pada indikator gaya kepemimpinan menurut Thoha (2014) sebagai berikut:

1) Perilaku instruktif (X1.1) rencana kegiatan semata-mata menjadi wewenang pimpinan, yang kemuadian diarahkan pada bawahannya. Indikator ini diukur dengan persepsi responden mengenai pimpinan yang memberikan pengarahan tentang rencana kegiatan.

2) Perilaku konsultatif (X1.2) yaitu pimpinan yang menggunakan komunikasi dua arah dan mendengarkan keluhan bawahan tentang keputusan yang diambil. Diukur dengan persepsi responden mengenai pimpinan yang bersedia mendengarkan keluhan bawahan tentang keputusan yang diambil.

3) Perilaku parsitipatif (X1.3) yaitu pimpinan dan bawahan dalam pemecahan masalah dan pengambilan keputusan sama-sama terlibat. Indikator ini diukur dengan persepsi responden pimpinan mengikut sertakan pegawai dalam pemecahan masalah organisasi.

4) Perilaku delegatif (X1.4) yaitu pimpinan mendiskusikan masalah-masalah yang dihadapi dengan bawahannya dan mendelegasikan pengambilan keputusan kepada 
Pengaruh Gaya Kepemimpinan terhadap Motivasi Kerja Karyawan Departemen Housekeeping di Hotel A Ubud Maharani, Indrayani, Diwyarthi

bawahannya. Indikator ini diukur dengan persepsi responden mengenai pimpinan yang selalu mendiskusikan masalah yang dihadapi pegawai dalam bekerja.

5) Kepemimpinan suportif (X1.5) yaitu melakukan berbagai usaha untuk membuat pekerjaan menjadi lebih menyenangkan. Indikator ini diukur dengan persepsi responden mengenai pimpinan yang berusaha membuat pekerjaan lebih menyenangkan.

Motivasi merupakan daya pendorong yang mengarahkan pegawai untuk bekerja lebih baik dan berkualitas, memiliki rasa tanggung jawab serta berupaya untuk meningkatkan prestasi kerja. Motivasi dapat diukur dengan indikator (Kartika dan Kaihatu, 2010):

1) Arahan perilaku (Y1) yaitu mengacu pada perilaku yang dipilih seseorang dalam bekerja dari banyak pilihan perilaku yang dapat mereka jalankan baik tetap maupun tidak. Indikator ini diukur dengan keinginan pegawai untuk maju dalam upaya menyelenggarakan pelayanan teknis administrasi kepegawaian yang prima

2) Tingkat usaha (Y2) yaitu mengenai seberapa keras usaha seseorang untuk bekerja sesuai dengan perilaku yang dipilih. Indikator ini diukur dengan usaha pegawai untuk mencapai prestasi kerja dalam upaya meningkatkan kualitas

3) Tingkat kegigihan (Y3) yaitu mengacu pada motivasi pegawai ketika dihadapkan pada suatu masalah, rintangan atau halangan dalam bekerja, seberapa keras seorang pegawai tersebut terus berusaha untuk menjalankan perilaku yang dipilih. Indikator ini diukur dengan usaha pegawai untuk selalu gigih dalam menyelesaikan pekerjaan agar dapat memberikan pelayanan yang terbaik.

\subsection{Teknik Analisis Data}

Teknik analisis data dalam penelitian ini menggunakan analisis regresi sederhana untuk mengetahui pengaruh variabel independen terhadap variabel dependen. Sebelum melakukan uji hipotesis terlebih dahulu menguji analisis kualitas data dengan uji validitas dan realiabilitas kemudian dilakukan uji asumsi klasik yang terdiri dari uji normalitas dan uji heterokedastisitas.

\section{HASIL DAN PEMBAHASAN}

\subsection{Karakteristik Responden}

Pengumpulan data dilakukan melalui penyebaran kuesioner kepada 42 orang karyawan Hotel A Ubud, sebelum terjadinya pengurangan pegawai akibat pandemi Covid, sebab pengurangan pegawai terjadi baru tahun 2021, sedangkan penelitian ini dilakukan penyebaran kuesioner pada bulan Oktober 2020. Penyebaran kuesioner dilakukan secara online dari google form. Penyebaran kuesioner dilakukan selama tiga hari yaitu mulai tangal 12 Oktober sampai 14 Oktober 2020 dengan usable response rate sebesar 100 persen.

Berdasarkan hasil pendistribusian kuesioner, responden dalam penelitian ini terdiri dari 42 karyawan Housekeeping Hotel A Ubud, dimana yang laki-laki berjumlah 20 orang, sedangkan perempuan sebanyak 22 orang. Dilihat dari segi usia, menunjukkan bahwa responden berasal dari berbagai kelompok usia, yaitu dari anak muda hingga orang dewasa, namun mayoritas responden berada pada rentang usia 41 sampai 50 tahun, artinya pada rentang usia 41-50 tahun karyawan memiliki pengalaman, kepercayaan diri yang tinggi, dan keterampilan yang menjadi faktor utama keunggulan dalam bekerja. Rentang usia ini juga menunjukkan tahap mengejar puncak karier, sehingga mempengaruhi motivasi kerja pegawai untuk bekerja lebih optimal sebelum tiba masa pensiunnya.

Ditinjau dari jenjang pendidikan terakhir, menunjukkan bahwa dominasi responden adalah lulusan SMA/SMK. Hal ini berarti bahwa pegawai memiliki kualitas dan integritas yang cukup baik karena sudah dibekali teori dan praktek yang cukup mumpuni pada masa 
Pengaruh Gaya Kepemimpinan terhadap Motivasi Kerja Karyawan Departemen Housekeeping di Hotel A Ubud Maharani, Indrayani, Diwyarthi

SMA/SMK, sehingga akan menunjang kinerja pegawai di Hotel A Ubud yang semakin meningkat. Pengelompokkan responden berdasarkan masa kerja menunjukkan bahwa karyawan mayoritas sudah bekerja di Hotel A Ubud selama lebih dari sepuluh tahun yang menunjukkan bahwa responden sudah memiliki sikap loyalitas yang tinggi pada Hotel A Ubud.

\subsection{Hasil Uji Validitas dan Reliabilitas}

Untuk menguji instrumen penelitian dilakukan uji validasi dan uji reliabiltas sebelum data dianalisis lebih lanjut. Kedua pengujian dilakukan dengan tujuan untuk mengukur apakah item - item instrumen penelitian yang digunakan pada penelitian ini sudah valid atau reliabel. Suatu instrumen dikatakan valid apabila memiliki koefisien korelasi antara butir dengan skor total dalam instrumen tersebut lebih besar dari 0,30 dengan tingkat kesalahan Alpha 0,05. Hasil rekapitulasi uji validitas dalam penelitian ini disajikan dalam Tabel 2 sebagai berikut:

Tabel 1: Hasil Uji Validitas

\begin{tabular}{ccccc}
\hline Variabel & Indikator & $\begin{array}{c}\text { Koefisien } \\
\text { Korelasi }\end{array}$ & $\begin{array}{c}\text { Sig. } \\
\text { (2tailed) }\end{array}$ & Keterangan \\
\hline Gaya & $\mathrm{X} 1$ & 0,958 & 0,000 & Valid \\
kepemimpinan & $\mathrm{X} 2$ & 0,955 & 0,000 & Valid \\
(X) & $\mathrm{X} 3$ & 0,891 & 0,000 & Valid \\
& $\mathrm{X} 4$ & 0,904 & 0,000 & Valid \\
Motivasi kerja & $\mathrm{X} 5$ & 0,879 & 0,000 & Valid \\
(Y) & Y2 & 0,985 & 0,000 & Valid \\
& Y3 & 0,982 & 0,000 & Valid \\
\hline
\end{tabular}

Uji Reliabilitas terhadap instrumen penelitian ini menggunakan nilai Alpha Cronbach, yakni untuk mengetahui unidimensionalitas butir-butir pernyataan terhadap variabel laten yang diteliti (Gaya Kepemimpinan dan Motivasi kerja). Nilai Alpha Cronbach dinyatakan reliabel jika nilainya lebih besar atau sama dengan 0,60. Rekapitulasi hasil uji reliabilitas instrumen penelitian dapat dilihat pada Tabel 2 berikut.

Tabel 2 : Hasil Uji Reliabilitas

\begin{tabular}{clcc}
\hline \multirow{2}{*}{ No. } & Variabel & $\begin{array}{c}\text { Cronbach's } \\
\text { Alpha }\end{array}$ & Keterangan \\
\hline 1 & Gaya kepemimpinan $(\mathrm{X})$ & 0,952 & Reliabel \\
2 & Motivasi kerja $(\mathrm{Y})$ & 0,985 & Reliabel \\
\hline
\end{tabular}

Hasil uji reliabilitas pada Tabel 2 menunjukkan bahwa seluruh instrumen penelitian memiliki koefisien Cronbach's Alpha lebih dari 0,60. Hal ini dapat dikatakan bahwa semua instrumen reliabel sehingga dapat digunakan untuk melakukan penelitian.

\subsection{Deskripsi Jawaban Responden}

Indikator gaya kepemimpinan dalam penelitian ini diukur dengan menggunakan lima pernyataan yang merefleksikan indikator gaya kepemimpinan pada Hotel A Ubud. Penilaian responden terhadap indikator penelitian diterjemahkan ke dalam lima kriteria pengukuran berdasarkan nilai intervalnya. Kriteria pengukuran tersebut menunjukkan bahwa semakin tinggi nilai yang diperoleh menunjukkan semakin baik tanggapan responden terhadap item pernyataan tersebut. Adapun skala pengukuran dan kriteria yang dimaksud dapat dilihat pada Tabel 3. 
Pengaruh Gaya Kepemimpinan terhadap Motivasi Kerja Karyawan Departemen Housekeeping di Hotel A Ubud Maharani, Indrayani, Diwyarthi

Tabel 3: Kriteria Pengukuran Tanggapan Responden

[Sumber: Sugiyono, 2016:32]

\begin{tabular}{lcc}
\hline No & Skala Pengukuran & Kriteria \\
\hline 1 & $1,00-1,80$ & Sangat rendah \\
2 & $1,81-2,60$ & Rendah \\
3 & $2,61-3,40$ & Sedang \\
4 & $3,41-4,20$ & Tinggi \\
5 & $4,21-5,00$ & Sangat Tinggi \\
\hline
\end{tabular}

Berdasarkan pada skala pengukuran dan kriteria yang ditampilkan pada Tabel 3, rata-rata jawaban responden terhadap variabel gaya kepemimpinan dan kriterianya dapat dilihat pada Tabel 4.

Tabel 4: Deskripsi Jawaban Responden Terhadap Indikator Gaya Kepemimpinan

\begin{tabular}{llcc}
\hline No & \multicolumn{1}{c}{ Pernyataan } & Rata-Rata & Kriteria \\
\hline 1 & $\begin{array}{l}\text { Pimpinan memberikan } \\
\text { pengarahan tentang rencana } \\
\text { kegiatan. }\end{array}$ & Tinggi \\
$2 \quad \begin{array}{l}\text { Pimpinan bersedia mendengarkan } \\
\text { keluhan bawahan tentang keputusan } \\
\text { yang diambil. }\end{array}$ & 3,64 & Tinggi \\
3 & $\begin{array}{l}\text { Pimpinan mengikut sertakan } \\
\text { pegawai dalam pemecahamasalah } \\
\text { organisasi }\end{array}$ & 3,71 & Tinggi \\
$4 \quad \begin{array}{l}\text { Pimpinan mendiskusikan masalah } \\
\text { yang dihadapi pegawai dalam } \\
\text { bekerja. }\end{array}$ & 3,60 & Tinggi \\
\hline $\begin{array}{l}\text { Pimpinan berusahamembuat } \\
\text { pekerjaan menjadi lebih mudah }\end{array}$ & 3,74 & Tinggi \\
\hline$\quad$ Rata-rata Jawaban & 3,70 & Tinggi \\
\hline
\end{tabular}

Tabel 4 menunjukkan rata-rata untuk indikator gaya kepemimpinan adalah sebesar 3,70, hal ini berarti secara umum responden setuju terhadap pernyataan-pernyataan yang terdapat pada indikator gaya kepemimpinan. Hasil ini memberikan informasi bahwa Hotel A Ubud memiliki gaya kepemimpinan yang baik. Nilai rata-rata tertinggi terdapat pada pernyataan "Pimpinan memberikan pengarahan tentang rencana kegiatan" dengan nilai rata-rata 3,79. Hal ini menunjukkan bahwa sebagian besar karyawan yang menjadi responden dalam penelitian ini menilai bahwa pimpinan Hotel A Ubud sudah memberikan pengarahan tentang rencana kegiatan dengan baik pada karyawannya

Indikator motivasi kerja dalam penelitian ini diukur dengan menggunakan tiga pernyataan yang berhubungan dengan motivasi kerja karyawan pada Hotel A Ubud. Tabel 5 berikut merupakan jawaban responden terhadap variabel motivasi kerja karyawan. 
Pengaruh Gaya Kepemimpinan terhadap Motivasi Kerja Karyawan Departemen Housekeeping di Hotel A Ubud Maharani, Indrayani, Diwyarthi

Tabel 5: Deskripsi Jawaban Responden Terhadap Indikator Motivasi kerja

\begin{tabular}{clcc}
\hline No & \multicolumn{1}{c}{ Pernyataan } & Rata-Rata & Kriteria \\
\hline 1 & $\begin{array}{l}\text { Saya memiliki keinginan untukmaju dalam } \\
\text { upaya meningkatkan karir }\end{array}$ & 3,74 & Tinggi \\
$2 \begin{array}{l}\text { Saya berusaha untuk mencapaiprestasi kerja } \\
\text { dalam upaya meningkatkan } \\
\text { kualitas karir. }\end{array}$ & 3,86 & Tinggi \\
$\begin{array}{l}\text { Saya selalu gigihdalam menyelesaikan } \\
\text { pekerjaan agar dapat memberikan pelayanan } \\
\text { yang } \\
\text { terbaik }\end{array}$ & 3,79 & Tinggi \\
\hline & & 3,79 & Tinggi \\
\hline
\end{tabular}

Tabel 5 menunjukkan rata-rata untuk indikator motivasi kerja adalah sebesar 3,79, hal ini berarti secara umum responden setuju terhadap pernyataan- pernyataan yang terdapat pada indikator motivasi kerja. Hasil penyebaran kuesioner memberikan informasi bahwa karyawan Hotel A Ubud sudah memiliki motivasi kerja yang tinggi. Nilai rata-rata tertinggi terdapat pada pernyataan "Saya berusaha untuk mencapai prestasi kerja dalam upaya meningkatkan kualitas karir" dengan nilai rata-rata 3,86. Hal ini menunjukkan bahwa karyawan Hotel A Ubud selalu berusaha untuk mencapai prestasi kerja dalam upaya meningkatkan kualitas karir yang menunjukkan rasa motivasi kerja yang tinggi.

\subsection{Hasil Uji Regresi}

Perhitungan koefisien regresi linier berganda dilakukan dengan analisis regresi melalui software SPSS 18.0 for Windows, diperoleh hasil yang ditunjukan pada Tabel 5.

Berdasarkan hasil analisis regresi linier sederhana seperti yang disajikan pada Tabel 5, maka dapat dibuat persamaan regresi sebagai berikut:

$$
\mathrm{Y}=0,424+0,593 \mathrm{X}+\mathrm{e}
$$

Nilai koefisien regresi variabel bebas memiliki nilai signifikansi uji t kurang dari 0,05. Hal ini menunjukkan bahwa variabel bebas memiliki pengaruh yang signifikan terhadap variabel terikat.

Tabel 5: Hasil Analisis Regresi Linier Berganda

\begin{tabular}{llrrrrrr}
\hline Model & & \multicolumn{2}{c}{$\begin{array}{l}\text { Unstandardized } \\
\text { Coefficients }\end{array}$} & \multicolumn{2}{c}{$\begin{array}{l}\text { Standardized } \\
\text { Coefficients }\end{array}$} & & \\
\cline { 3 - 6 } & & \multicolumn{2}{c}{ B } & Std. Error & Beta & & \multirow{2}{*}{ Sig. } \\
\cline { 3 - 6 } 1 & (Constant) & .424 & 2.239 & .189 & .851 \\
& Gaya kepemimpinan & .593 & .119 & .619 & 4.989 & .000 \\
\hline
\end{tabular}

Koefisien determinasi (R2) digunakan untuk mengetahui dan mengukur kemampuan model dalam menerangkan variasi variabel independen. Peneliti menggunakan nilai adjusted R2 pada saat mengevaluasi yang mana model regresi terbaik, karena tidak seperti R2, nilai adjusted R2 dapat naik atau turun apabila satu variabel independen ditambahkan ke dalam model. 
Pengaruh Gaya Kepemimpinan terhadap Motivasi Kerja Karyawan Departemen Housekeeping di Hotel A Ubud Maharani, Indrayani, Diwyarthi

Tabel 6: Hasil Uji Koefisien Determinasi $\left(\mathrm{R}^{2}\right)$

\begin{tabular}{ccccc}
\hline Model & $\mathrm{R}$ & $\mathrm{R}$ Square & Adjusted R Square & $\begin{array}{c}\text { Std. Error of the } \\
\text { Estimate }\end{array}$ \\
\hline 1 & $0,619^{\mathrm{a}}$ & 0,384 & 0,368 & 2,81421 \\
\hline
\end{tabular}

Hasil uji pada Tabel 6 memberikan hasil dimana diperoleh besarnya adjusted R2 (koefisien determinasi yang telah disesuaikan) adalah sebesar 0,368. Ini berarti variasi Motivasi kerja dapat dipengaruhi secara signifikan oleh variabel gaya kepemimpinan sebesar 36,8 persen, sedangkan sisanya sebesar 63,2 persen dijelaskan oleh faktor-faktor lain yang tidak dijelaskan dalam model penelitian. Dari hasil ini dapat disimpulkan walaupun gaya kepemimpinan berpengaruh positif terhadap motivasi kerja karyawan, tetapi pengaruhnya moderat cenderung lemah. Hal ini mengindikasikan bahwa gaya kepemimpinan bukanlah satu-satunya variabel yang mempengaruhi motivasi kerja karyawan. Terlebih pada situasi pandemi saat ini, dimana variabel lain yang berpotensi dapat mempengaruhi motivasi kerja selain gaya kepemimpinan antara lain kompensasi (Setyorini, Yuesti, Landra, 2018), jaminan Kesehatan, job security (Ahmad and Jameel, 2018), serta lingkungan kerja (Rasheed dkk, 2020).

Pengaruh variabel gaya kepemimpinan terhadap Motivasi kerja pegawai yang diuji dengan menggunakan Uji t. Kriteria pengujian untuk menjelaskan interpretasi pengaruh variabel yakni apabila nilai signifikansi $<0,05$ maka H0 ditolak dan H1 diterima. Sebaliknya, jika nilai signifikansi > 0,05 maka H0 diterima dan H1 ditolak. Berdasarkan hasil analisis pengaruh gaya kepemimpinan terhadap Motivasi kerja diperoleh nilai signifikasi sebesar 0,000 dengan nilai koefisien regresi sebesar 0,593 dan nilai t hitung positif sebesar 4,989. Nilai Signifikansi 0,000 0,05 mengindikasikan bahwa Hipotesis diterima. Hasil ini mempunyai arti bahwa Gaya kepemimpinan berpengaruh positif dan signifikan terhadap Motivasi kerja.

\subsection{Pembahasan}

Hasil analisis dalam penelitian ini menunjukkan bahwa gaya kepemimpinan berpengaruh positif dan signifikan terhadap motivasi kerja. Hal ini berarti bahwa semakin baik gaya kepemimpinan yang diterapkan oleh Hotel A Ubud, maka motivasi kerja karyawan akan semakin meningkat. Melalui gaya kepemimpinan, diharapkan motivasi kerja karyawan akan meningkat. Walaupun gaya kepemimpinan terbukti bukan satusatunya cara untuk meningkatkan motivasi kerja karyawan, namun pengaruhnya signifikan dan patut diperhatikan oleh pemimpin organisasi.

Gaya kepemimpinan manajer berpengaruh signifikan terhadap motivasi karyawan, baik secara langsung atau tidak langsung (Hasanah, 2018; Prayudi, 2020). Karakteristik pemimpin yang berbeda dapat menghasilkan tingkat motivasi yang berbeda (Hamidi, 2020). Mengko (2021) menyatakan bahwa motivasi dipengaruhi oleh perbedaan karakter pemimpin dan pemahaman pekerjaan dalam setiap situasi yang tercermin pada gaya kepemimpinannya. Ada banyak komponen motivasi yang mungkin berdampak pada pemimpin. Oleh karena itu, para pemimpin tidak boleh membiarkan situasi yang menurunkan motivasi kerja (Chaundhary, 2012; Zhang et al., 2020). Gaya kepemimpinan mempengaruhi motivasi, sebab dengan adanya penerapan gaya kepemimpinan yang baik maka pemimpin dapat memahami dan melaksanakan tugasnya secara efektif sehingga mampu memberikan arahan dan motivasi pada karyawanya agar mampu melaksanakan tugas yang diemban para pegawai tersebut (Mohelska dan Sokolova, 2015)

Hasil ini berarti bahwa semakin baik penerapan gaya kepemimpinan pada sebuah perusahaan, maka dapat membentuk motivasi kerja yang semakin tinggi. Perilaku pemimpin akan memberikan motivasi sepanjang membuat bawahan merasa butuh 
Pengaruh Gaya Kepemimpinan terhadap Motivasi Kerja Karyawan Departemen Housekeeping di Hotel A Ubud Maharani, Indrayani, Diwyarthi

kepuasan dalam pencapaian kinerja yang efektif dan menyediakan ajaran, arahan, dukungan dan penghargaan yang diperlukan dalam kinerja efektif. Hasil penelitian ini konsisten dengan hasil penelitian yang dilakukan oleh Pradana (2015), Afrizal (2015), Lisnawati (2016), Prihandayani (2017), Ali (2017), Farfalonni dan Prasetio (2017), serta Setyorini et al. yang menemukan hasil bahwa gaya kepemimpinan berpengaruh positif dan signifikan terhadap motivasi kerja pegawai.

\section{KESIMPULAN}

Berdasarkan hasil penelitian dan pembahasan pada bab sebelumnya maka dapat disimpulkan bahwa gaya kepemimpinan berpengaruh positif dan signifikan terhadap motivasi kerja pegawai karena memiliki nilai koefisien regresi yang positif sebesar 0,593 dengan tingkat signifikansi sebesar $0,000<0,05$. Hasil ini berarti bahwa semakin baik penerapan gaya kepemimpinan pada sebuah perusahaan, maka dapat membentuk motivasi kerja yang semakin tinggi. Pemimpin yang memiliki gaya kepemimpinan sesuai bagi karyawannya serta dapat menciptakan hubungan yang harmonis antara atasan dan bawahan, kemudian dapat membuat suasana kerja yang nyaman serta dapat membangun hubungan yang harmonis antara atasan dan bawahan, maka tidak menutup kemungkinan karyawannya memiliki motivasi kerja yang tinggi, hal tersebut dikarenakan pengaruh gaya kepemimpinan terhadap motivasi kerja karyawan cukup tinggi.

Sehubungan dengan simpulan tersebut, maka saran yang dapat diberikan adalah agar pimpinan Hotel A Ubud dapat mengembangkan kemampuan dirinya terutama dalam hal mendefinisikan peranan masing-masing bawahannya, kemudian memberikan arahan yang terstruktur dan sportif, serta melibatkan bawahannya dalam pengambilan suatu keputusan untuk hal-hal tertentu yang berkaitan dengan kelancaran operasional Hotel A Ubud tersebut, sehingga dapat mempengaruhi motivasi kerja pegawainya. Pemimpin sebaiknya lebih memberikan pengarahan tentang rencana kegiatan kerja bagi karyawan departemen housekeeping, kemudian bersedia mendengarkan keluhan karyawan, mengikut sertakan karyawan dalam pemecahanan masalah organisasi dan berusaha membuat pekerjaan menjadi lebih mudah. Pemimpin juga harus meningkatkan feedback positif bagi karyawan seperti lebih mendiskusikan masalah yang dihadapi pegawai dalam bekerja.

Hasil uji koefisien determinasi menunjukkan sebesar 36,8 persen variabel motivasi kerja dipengaruhi oleh gaya kepemimpinan, sedangkan sisanya sebesar 63,2 persen dijelaskan oleh faktor-faktor lain, sehingga disarankan bagi penelitian selanjutnya untuk menganalisis variabel lainya seperti seperti variabel kompensasi, variabel program kesehatan dan keselamatan kerja dan variabel lingkungan kerja. Selain itu, penelitian ini dilakukan pada ruang lingkup yang terbatas sehingga hasilnya tidak dapat digeneralisasi. Rekomendasi untuk pengembangan penelitian ke depan adalah memperluas cakupan studinya tidak hanya pada satu departemen pada satu hotel, tetapi pada beberapa hotel di satu area tertentu. Keterbatasan lainnya adalah penelitian ini dilakukan secara crosssectional sehingga pada penelitian lanjutan dapat dikembangkan menjadi penelitian longitudinal atau time series.

\section{DAFTAR PUSTAKA}

Afrizal, A.. (2016). Pengaruh Gaya Kepemimpinan Terhadap Motivasi Kerja Dan Kepuasan Kerja Serta Dampak Pada Kinerja Karyawan. JESI Ournal Ekonomi Syariah Indonesia), 5(2), 1-20.

Ahmad, M. A., \& Jameel, A. S. (2018). Factors Affecting on Job Satisfaction Among Academic Staff. Polytechnic Journal, 8(2). https://ssrn.com/abstract=3205949

Ali, M. (2017). Pengaruh Gaya Kepemimpinan Terhadap Motivasi Kerja Pegawai. Jurnal Ji@P, 4(1), 27-45 
Pengaruh Gaya Kepemimpinan terhadap Motivasi Kerja Karyawan Departemen Housekeeping di Hotel A Ubud Maharani, Indrayani, Diwyarthi

Al-Sada, M., Al-Esmael, B., \& Faisal, M.N. (2017). Influence of organizational culture and leadership style on employee satisfaction, commitment and motivation in the educational sector in Qatar. EuroMed Journal of Business, 12(2), 163-188. https://doi.org/10.1108/EMJB-02-2016-0003

Chaerunnisa, F. (2016). Pengaruh Kepemimpinan Dan Budaya Organisasi Terhadap Kinerja Karyawan Pada Fabu Hotel Bandung. Jurnal Fakultas Ekonomi Dan Bisnis Unpas, 1-10.

Chaundhary, N. (2012). Impact of Employee Motivation on Performance (Productivity) In Private Organization. International Journal of Business Trends and Technology, 2(4).

Farfalonni, H., \& Prasetio, A.P. (2017). Pengaruh Gaya Kepemimpinan Terhadap Motivasi Kerja Karyawan Pt . Mustika Ratu Cabang Bandung. Jurnal Ilmu-Ilmu Sosial Dan Humaniora, 19(2), 62-75.

Flippo, E.B. (2001). Manajemen Personalia. Jakarta: PT. Gramedia.

Hamidi. (2020). Pengaruh Gaya Kepemimpinan Dan Motivasi Kerja Terhadap Kinerja Karyawan. Dimensi, 9(1), 1-16.

Hasanah, N. (2018). Pengaruh Gaya Kepemimpinan Dan Motivasi Kerja Terhadap Disiplin Kerja Karyawan Treepark Hotel Banjarmasin (Studi Kasus Pada Intro Bistro). Jurnal Ilmiah Ekonomi Bisnis, 4(1), 69-76.

Indrayani, I. G. A. P. W. (2018). Leadership Style and Organisational Commitment: An Empirical Study of Star Hotels. International Journal of Multidisciplinary Educational Research, 8 (2), 124-132.

Kartika, E. W., \& Kaihatu, T. S. (2010). Analisis Pengaruh Motivasi Kerja Terhadap Kepuasan Kerja (Studi Kasus pada Karyawan Restoran di Pakuwon Food Festival Surabaya). Jurnal Manajemen dan Kewirausahaan, 12(1), 100-112.

Kiswanto, M.H., \& Sutarso, J. (2018). Pengaruh Gaya Kepemimpinan Terhadap Motivasi Bekerja Karyawan Kantor Dinas KOMINFO Surakarta. Universitas Muhammadiyah Surakarta.

Lisnawati, N. W. (2016). Pengaruh Komunikasi Dan Gaya Kepemimpinan Terhadap Semangat Kerja Karyawan Di Fontana Hotel Bali. E-Jurnal Manajemen Universitas Udayana, 1-16.

Mengko, S. (2021). Pengaruh Gaya Kepemimpinan Pacesetting Terhadap Motivasi Kerja Karyawan F \& B Service Departement Pada Sintesa Peninsula Hotel Manado. Hospitality and Tourism, 3(2). https://doi.org/https://doi.org/10.35729/jhp.v3i2.63

Mohelska, H., \& Sokolova, M. (2015). Organizational Culture and Leadership-Joint Vessels? Procedia: Social and Behavioral Sciences, 171, 1011-1016.

Pradana, M. (2015). Pengaruh Gaya Kepemimpinan Terhadap Motivasi Karyawan di Ganesha Operation, Bandung. Jurnal Studi Manajemen Dan Bisnis, 2(1), 1-16.

Prayudi, A. (2020). Pengaruh Gaya Kepemimpinan Transformasional Terhadap Kinerja Karyawan Dengan Motivasi Kerja Sebagai Variabel Intervening. Jurnal Manajemen, 6(2), 63-72.

Prihandayani, H. (2017). Pengaruh Gaya Kepemimpinan, Motivasi, Budaya Organisasi Dan Lingkungan Kerja Terhadap Kinerja Karyawan (Studi Kasus Pada PD. BKK SeKabupaten Wonogiri). Naskah Publikasi, 1-19.

Rasheed, M.I., Jamad, W.N., dkk. (2020). Perceived Compensation Fairness, Job Design, and Employee Motivation: The Mediating Role of Working Environment. South Asian Journal of Management Sciences, 14(2), 229-246. http://10.21621/sajms.2020142.05

Safitri, R.P. (2018). Pengaruh Budaya Perusahaan Terhadap Motivasi Kerja Dan Dampaknya Pada Kinerja Karyawan. Journal of Management Review.

Setyorini, R. W., Yuesti, A., \& Landra, N. (2018). The Effect of Situational Leadership Style and Compensation to Employee Performance with Job Satisfaction as Intervening 
Pengaruh Gaya Kepemimpinan terhadap Motivasi Kerja Karyawan Departemen Housekeeping di Hotel A Ubud Maharani, Indrayani, Diwyarthi

Variable at PT Bank Rakyat Indonesia (Persero), Tbk Denpasar Branch. International Journal of Contemporary Research and Review, 9(8), 20974-20985. https://doi.org/10.15520/ijcrr/2018/9/08/570

Simamora, H. (2014). Manajemen Sumber Daya Manusia. Yogyakarta: Sekolah Tinggi YKPN Sugiyono. (2016). Metode Penelitian Bisnis. Bandung: Alfabeta.

Supriadi, D., \& Endang Riswana. (2017). Pengaruh Gaya Kepemimpinan Terhadap Motivasi Kerja Pegawai Sekolah Tinggi Ilmu Kesehatan (STIKES) Kharisma Karawang. Jurnal Manajemen \& Bisnis Kreatif, 2(1), 46-81.

Surbakti, M. (2016). Pengaruh Gaya Kepemimpinan Terhadap Motivasi Kerja Karyawan Pada PT. Riau Media Televisi. E-Journal Mahasiswa Prodi Manajemen, 3(1), 1-10.

Thoha, M. (2014). Perilaku Organisasi: Konsep Dasar dan Aplikasinya, Cetakan ke-23. Jakarta: Rajawali Pers

Wibowo, E. A., \& Prasetyo, E. (2015). Analisa Pengaruh Gaya Kepemimpinan Terhadap Motivasi Kerja Karyawan Di Restoran X. Jurnal Hospitality Dan Manajemen Jasa, 3(1), 354-70.

Woszczyna, K. S. (2015). Leadership and Organizational Culture as the Normative Influence of Top Management on Employee's Behaviour in the Innovation Process. Journal of Business Economics and Management, 34, 396-402.

Wowor, W. Q., Sumayku, S.M. \& Sambul, S. A. P. (2019). Pengaruh Gaya Kepemimpinan Terhadap Motivasi Kerja Karyawan Pada PT. Matahari Departement Store Di MegaMall, Manado. Jurnal Administrasi Bisnis, 8(2), 107-11.

Yukl, G. (2015). Leadership in Organizations, Seventh Edition. PT. Indeks, Jakarta.

Zhang, J., Xie, C., Wang, J., Morrison, A.M. and Coca-Stefaniak, J.A. (2020). Responding to a major global crisis: the effects of hotel safety leadership on employee safety behavior during COVID-19. International Journal of Contemporary Hospitality Management, 32(11), 3365-3389. https://doi.org/10.1108/IJCHM-04-2020-0335 